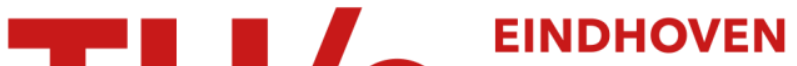 UNIVERSITY OF TECHNOLOGY
}

\section{Compensation Mechanism for Active Power Curtailment in LV Distribution Networks}

\section{Citation for published version (APA):}

Tomar, A., Haque, A. N. M. M., \& Nguyen, P. H. (2020). Compensation Mechanism for Active Power Curtailment in LV Distribution Networks. In Proceedings of 2020 IEEE PES Innovative Smart Grid Technologies Europe, ISGT-Europe 2020 (pp. 759-763). [9248836] Institute of Electrical and Electronics Engineers. https://doi.org/10.1109/ISGT-Europe47291.2020.9248836

DOI:

10.1109/ISGT-Europe47291.2020.9248836

Document status and date:

Published: 10/11/2020

\section{Document Version:}

Accepted manuscript including changes made at the peer-review stage

\section{Please check the document version of this publication:}

- A submitted manuscript is the version of the article upon submission and before peer-review. There can be important differences between the submitted version and the official published version of record. People interested in the research are advised to contact the author for the final version of the publication, or visit the $\mathrm{DOI}$ to the publisher's website.

- The final author version and the galley proof are versions of the publication after peer review.

- The final published version features the final layout of the paper including the volume, issue and page numbers.

Link to publication

\section{General rights}

Copyright and moral rights for the publications made accessible in the public portal are retained by the authors and/or other copyright owners and it is a condition of accessing publications that users recognise and abide by the legal requirements associated with these rights.

- Users may download and print one copy of any publication from the public portal for the purpose of private study or research.

- You may not further distribute the material or use it for any profit-making activity or commercial gain

- You may freely distribute the URL identifying the publication in the public portal.

If the publication is distributed under the terms of Article 25fa of the Dutch Copyright Act, indicated by the "Taverne" license above, please follow below link for the End User Agreement:

www.tue.nl/taverne

Take down policy

If you believe that this document breaches copyright please contact us at:

openaccess@tue.nl

providing details and we will investigate your claim. 


\section{Compensation Mechanism for Active Power Curtailment in LV Distribution Networks}

\author{
Anuradha Tomar \\ Department of Electrical Engineering \\ Eindhoven University of Technology \\ Eindhoven, The Netherlands \\ a.tomar@tue.nl
}

\author{
A.N.M.M. Haque \\ Department of Electrical Engineering \\ Eindhoven University of Technology \\ Eindhoven, The Netherlands \\ A.N.M.M.Haque@ tue.nl
}

\author{
Phuong Nguyen \\ Department of Electrical Engineering \\ Eindhoven University of Technology \\ Eindhoven, The Netherlands \\ P.Nguyen.Hong@tue.nl
}

\begin{abstract}
Active power curtailment (APC) is being considered to tolerate overvoltage issues when PV installed capacity increases. The consequence is that prosumers are subjected to unwanted APC that ultimately results in less utilization of installed distributed energy resources (DERs). In this paper, a mechanism is proposed to compensate the prosumers for APC to make it a viable network service. The proposed compensation mechanism is based on the electricity price demand elasticity concept and would be more useful in countries where the electricity markets are not enough matured for providing curtailment compensations based on day-ahead market prices. The aim here is to develop a simplified method that should be simple as a fixed contract setting for compensation and have a better correlation with electricity price dynamics. To demonstrate the proposed compensation mechanism, a case study is presented, simulating a Dutch $\mathrm{LV}$ distribution network in MATLAB/Simulink environment. The results shared in this paper represents preliminary work, to give an insight.
\end{abstract}

Keywords- active power curtailment, congestion management, compensation mechanism, demand response.

\section{INTRODUCTION}

Higher penetration of renewable energy is beneficial for low carbon emissions, however, it becomes a challenging task for actors involved like Distribution System Operators (DSOs) to manage power flows considering existing grid constraints and future aspects [1]. With the increasing injection of distributed energy resources (DERs), especially solar PV congestion in the low voltage (LV) distribution network is becoming more prominent, and therefore mitigation techniques, curtailment strategies, and compensation methods are becoming more important and relevant [2].

In LV distribution networks, high penetration of DERs results in voltage or overloading problems, associated with the congested network. To regulate voltage in LV distribution networks, two consensus algorithms that minimize the required power curtailment and fairly divide the power curtailment among all participating PV systems are introduced in [3]. To optimize the peak load reduction, authors in [4] have presented a fuzzy logic-based data-driven model. Further, to perform solar and load curtailment together with a unified optimal net-load balancing framework that optimizes the curtailment cost is developed in [5]. Several strategies are being widely studied to tackle the challenges with direct switching actions such as load shedding or power curtailment [6]. Authors in [7] have presented a real-time congestion management mechanism to

This work was supported by UNITED-GRID project which has received funding from the European Community's Horizon 2020 Framework Programme under grant agreement no. 773717. This work is also partially supported by UNICORN project of Dutch Top Sector Energy.

XXX-X-XXXX-XXXX-X/XX/\$XX.00 @20XX IEEE solve the congestion problem at $\mathrm{MV} / \mathrm{LV}$ transformer considering the thermal overloading of the transformer. However, the need for a more sophisticated control mechanism has been identified to address the attributes of individual prosumers along with the development of compensation-based curtailment mechanisms for prosumers.

In Germany, PV system operators having the installed capacity of less than $30 \mathrm{~kW}$ are obliged to limit the PV power output to a threshold of $70 \%$ of the installed capacity. This leads to an additional loss of $30 \%$ power, that could be otherwise utilized [8]. Technical developments, energy policies, and regulations should exploit flexibility options, and on the other side, should also ensure that green energy investors, prosumers would be properly compensated [9]. Many CEER member countries are facing congestions in their networks [10]. The methods used for calculation of APC, associated costs, and allocation of corresponding compensations must be transparent and clear for involved actors [11].

As per the recommendations of regulatory policy, DSOs are allowed to perform curtailment. However, it is important to identify that compensation should be based on production cost, fixed contract, or depends on market prices [12]. The market-based compensation motivates DSOs to invest in the extension of grid capacity. However, fixed contract based compensation may re-locate their investors to the area where curtailment is least or may limit their investment due to expected losses based on fixed contracts. In principle, compensation should be based on the day-ahead market price and must include the value of lost incentive [13]. Compensation amount and policy should be framed such that it further motivates the investments in renewables [14]. The market-based approach considers curtailment as valuable service provided to ensure network constraints and system security [15].

On the contrary, many countries do not have matured energy markets and are still in the developing stage. As a present practice, many countries compensate DEGs, based on a fixed contract. Therefore, it is realized that there should be a compensation mechanism for APC that may not be as dynamic as the day-ahead market and not as static as a fixed contract based compensation method. Therefore, it is essential to develop an APC compensation mechanism that should hold the characteristics of electricity markets. Along with ease of implementation; similar to the fixed contract based compensation mechanisms.

Electricity price demand elasticity coefficient captures the dynamics of electricity market over a time period (short run 
or long run), and have a direct correlation between change in power demand and corresponding variations in prices. In this paper, an APC compensation method for prosumers, based on electricity price elasticity concept is proposed. The proposed method is an innovative approach, as it provides a compensation method for the countries where the energy market is not enough matured for allocating APC compensation based on the day-ahead market.

The rest of this paper is organized as follows: Section II presents the problem formulation. The description of the proposed compensation methodology is included in section III. A case study for the demonstration of the proposed compensation mechanism is presented in section IV. Section $\mathrm{V}$ concludes the main findings, limitations, and future scope of the presented work.

\section{Problem Statement}

Instantaneous loading of $\mathrm{LV}$ distribution transformer is defined as in (1) and (2):

$$
\begin{gathered}
P_{t}=V_{t} * I_{t} \\
P_{t}=\sum_{i=1}^{N} V_{f i} * I_{f i}
\end{gathered}
$$

where $P_{t}, V_{t}$ and $I_{t}$ are the instantaneous transformer power, voltage, and current values respectively. $N$ is defined as the number of feeders associated with the transformer. $V_{f}$ and $I_{f}$ are the voltage and current respectively, at the corresponding feeder. Loading of the transformer at any instant should be less than the maximum transformer loading defined for the safe operation of the transformer.

$$
P_{t} \leq P_{\max }
$$

where $P_{\max }$ is the maximum power loading level associated with the transformer above which it would be unsafe to operate the transformer.

In this work, congestions resulting from the reverse power flow from solar PV have been considered. Considering the case of a network with high PV penetration in the LV distribution network, the aim is to increase the utilization of available PV energy, thus minimizing the curtailment subject to the following constraints:

$$
\begin{gathered}
P_{P V \text { curt }}=\left|P_{t}-P_{\text {max }}\right| \\
\sum_{i=1}^{H} P_{\text {PVcurt }_{i}}=\left|P_{t}-P_{\max }\right|
\end{gathered}
$$

Here it is assumed that $H$ is the number of houses associated with the feeder and curtailed PV power $P_{P V \text { curt }}$ would be divided among $H$ houses in the ratio of their injected PV power as given in (6).

$$
P_{\text {PVcurt }_{i}}=\frac{P_{\text {PVinj }_{i}}}{\sum_{i=1}^{H} P_{\text {PVinj }_{i}}} * P_{P_{\text {V curt }}}
$$

where $P_{P \text { curt }}$ is the amount of PV power to be curtailed from $i^{\text {th }}$ house and $P_{P_{\text {Vinj }}}$ represents injected PV power.

In other words $P_{\text {PVcurt }_{i}}$ is the PV power which $i^{\text {th }}$ house prosumer could otherwise have utilized and have received some financial gains. However, due to the network constraints, DSO has decided to curtail it. In case of such frequent PV power curtailments, especially during the summer season, prosumer may get demotivated due to loss of benefits even by producing more PV power and may plan to shift their investments in other markets or regions that are subject to least curtailments. Also, it is important to understand that these prosumers serve as assets to the DSOs, as due to them only, DSOs can delay immediate high investment required for distribution network capacity extension. Therefore, it is justified to share compensation with prosumers for the amount of green energy being curtailed.

\section{COMPENSATION MECHANISM FOR APC}

The proposed compensation mechanism is based on the concept of electricity price demand elasticity and calculates the compensation for each prosumer subjected to power curtailment.

\section{A. Concept of Electricity Price Demand Elasticity}

Price elasticity of demand is an economics concept and can be expressed as the willingness of the customer to buy a certain product with corresponding changes in the product prices [16]. Electricity price demand elasticity is defined as the ratio of change in power demand to the change in price corresponding to power demand [17].

$$
\varepsilon=\frac{\Delta P_{d} / P_{d}}{\Delta E_{p} / E_{p}}
$$

Here $\varepsilon$ is the electricity price demand elasticity coefficient which indicates the relative change in demand of power that would result from a change in the price of power. $\Delta P_{d}$ and $P_{d}$ represents the change in power demand and power demand respectively. Further, $\Delta E_{p}$ and $E_{p}$ depicts the corresponding change in electricity prices and actual electricity prices respectively.

\section{B. Compensation Calculation}

Based on the electricity price demand elasticity concept, compensation for APC can be defined as in (8):

$$
C_{\text {omp }}=[E]^{-1} P_{P V \text { curt }}
$$

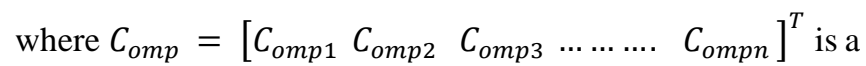
column vector of associated compensation to each house. $P_{P V \text { curt }}$ is also a column vector corresponding to the $\mathrm{PV}$ power to be curtailed from each house. $[E]$ is defined as in (9):

$$
E=\left[\begin{array}{ccc}
\varepsilon_{11} & \cdots & \varepsilon_{1 n} \\
\vdots & \ddots & \vdots \\
\varepsilon_{n 1} & \cdots & \varepsilon_{n n}
\end{array}\right]
$$

$\left[\begin{array}{ccc}\varepsilon_{11} & \ldots & \varepsilon_{1 n} \\ \vdots & \ddots & \vdots \\ \varepsilon_{n 1} & \ldots & \varepsilon_{n n}\end{array}\right]$ represents the elasticity coefficient matrix between change in power demand and change in electricity price for a residential prosumer.

Authors [18] have investigated electricity demand for 29 European countries and it was concluded that price elasticities are very small, especially in the short run, while the income elasticities are relatively large, especially for households and in the long run. The average prices that residential and industrial consumers paid were EUR 0.13 and EUR 0.09 per kWh, respectively. Estimation of electricity price demand elasticity for residential consumption has been 
studied in [19]-[24] for Portugal, India, Brazil, Germany, Canada, Nepal respectively. In [20] it was concluded that "one 'price' fits all" may not seem to be an effective policy in the Indian context. In the proposed work, $\varepsilon_{11}=\varepsilon_{1 n}=$ $\varepsilon_{n 1}=\varepsilon_{n n}=\varepsilon$ is assumed as constant for various intervals of the day considering the discussion presented in [18] regarding the inelastic and elastic behaviors of the residential electricity price demand elasticity. $\mathcal{E}$ is considered as 0.11 [18] for the compensation calculation.

Fig. 1 depicts the flowchart for the APC compensation mechanism. Based on the comparison between measured power level at the transformer and set overloading threshold values, DSO decides whether to proceed for APC or not. PV power curtailment is calculated as given in (6), based on the ratio of PV power injection in the distribution network.

Compensation signaling based on the electricity price demand concept enables DSO to prepare a compensation plan and thus to motivate the prosumers for investment in DERs. To calculate compensation, information about electricity price demand elasticity is required which varies country wise. It is important to note here that as per the conventional approach each prosumer has to support and execute the APC as per the scheduled plan without receiving any compensation for APC. However, in the proposed work, each prosumer will receive compensation, as otherwise curtailed energy could have been utilized and would have resulted in some economical gains to prosumers. The compensation signaling is shown in Fig. 1 is the key contribution of the proposed work.

\section{CASE STUdY}

\section{A. System Framework}

The configuration of the LV distribution network considered for the case study is depicted in Fig. 2, which is similar to a typical Dutch residential LV distribution network. The network consists of 20 houses and is fed from a 3-phase, $10 / 0.4 \mathrm{kV}, 100 \mathrm{kVA} \mathrm{MV/LV} \mathrm{transformer.} \mathrm{Each} \mathrm{house} \mathrm{in} \mathrm{the}$ network is assumed to have a PV as DERs, heat pumps, as controllable load and TV, lights, etc. as base loads. The network consists of underground power cables characterizing high $\mathrm{R} / \mathrm{X}$ ratios compared to overhead lines. Four different types of heat pumps, household characteristics, and installed PV capacities are considered and distributed among the 20 houses. A high PV injection is considered, assuming the summer season, as PV power curtailment will be more relevant in summers.

\section{B. Simulation Results \& Discussion}

The LV distribution network as shown in Fig. 2, without the implementation of APC, is considered as the uncontrolled case, and results thus obtained are compared with the results obtained by applying the proposed compensation-based APC mechanism. Simulation has been carried out for 24 hours duration. Fig. 3 depicts the power at MV/LV distribution transformer for both the uncontrolled and controlled cases. The transformer is considered overloaded when measured power exceeds the threshold value of 1 p.u. As expected in the uncontrolled case, no PV power would be planned to curtail. However, under a controlled scenario, as the transformer is overloaded, the PV power curtailment process is initiated to maintain loading within specified limits.

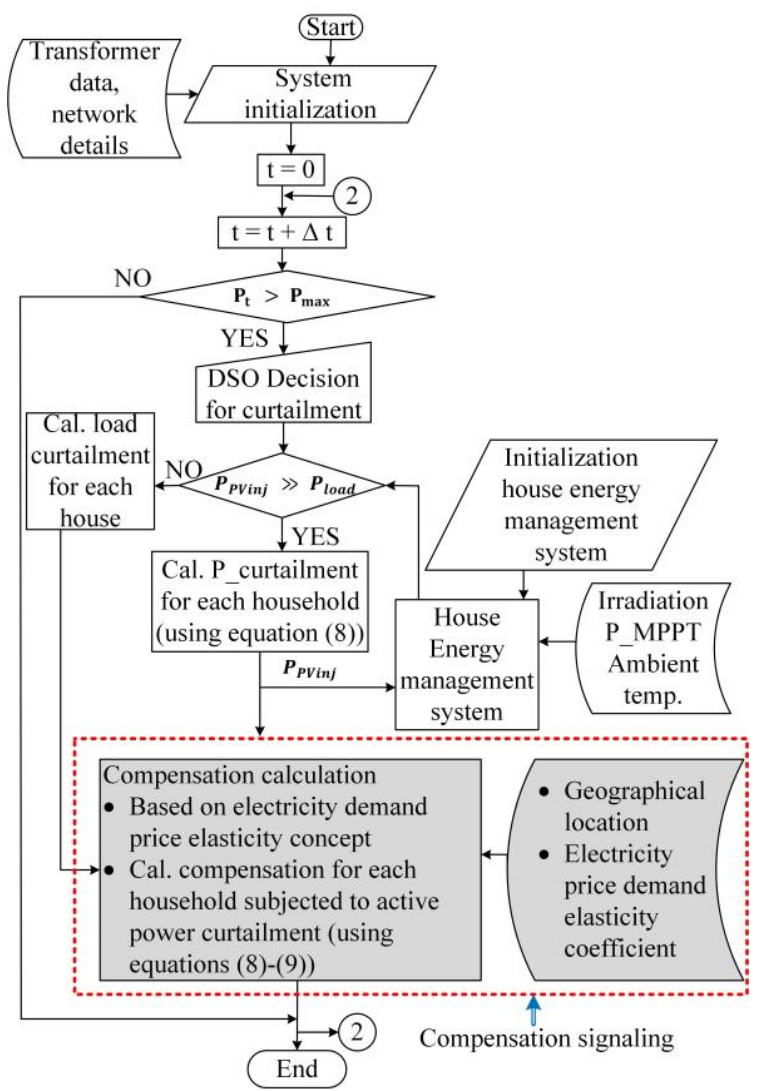

Fig. 1 Flowchart of the compensation mechanism

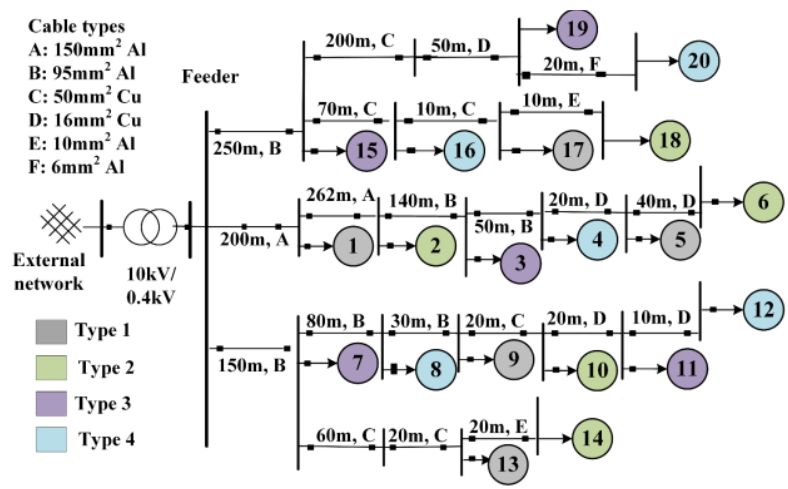

Fig. 2. Network configuration

To limit the overloading at the distribution transformer, PV power curtailment is calculated for each house in the proportion of the PV power being injected by each house as shown in Fig. 4. PV power being injected by each household under the uncontrolled and controlled case is shown in Fig. 5-6, respectively. Fig. 7, depicts the comparison of PV power being injected by house 9 . As expected, in controlled case PV power being injected by house 9 is less to execute the PV power curtailment plan. Similarly, other houses also support and execute the PV curtailment plan to reduce transformer overloading.

Calculated compensation for each prosumer, subjected to power curtailment is depicted in Fig. 8. The electricity price demand elasticity coefficient is considered as 0.11 [18]. Further, Fig. 9 depicts the total cost incurred to the DSO as 
compensation for prosumers. In the presented work a linear variation of electricity price demand elasticity is considered as it is relatively inelastic in the short run. However, a more exhaustive analysis could be carried out as an extension to this work, in order to obtain optimized results.

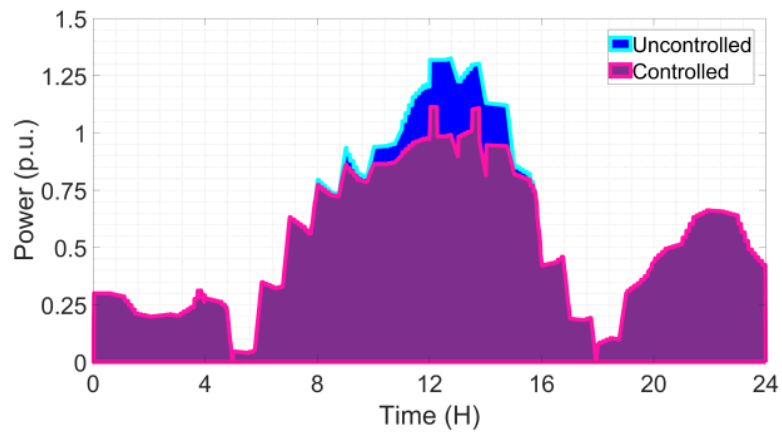

Fig. 3. Transformer power under uncontrolled and controlled scenarios

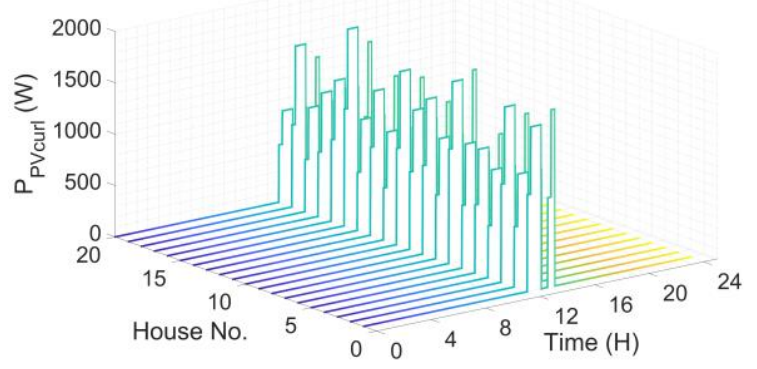

Fig. 4. PV curtailment plan for each house

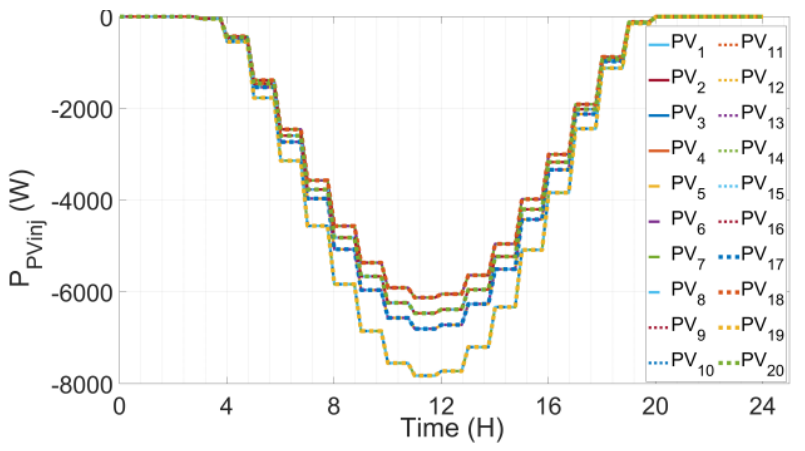

Fig. 5. Injected PV power by each household in uncontrolled case

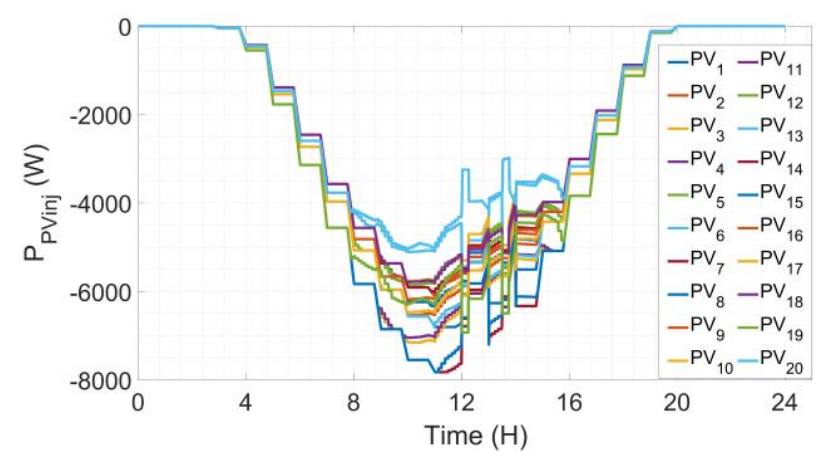

Fig. 6. Injected PV power by each household in controlled case

In the absence of proper compensation mechanism for APC, prosumers planning for the installation of DERs may analyze the present curtailment scenario and it may be possible that they do not opt for higher capacity DERs. Due to the fact that power curtailment would not lead them to utilize the installed capacity in maximized manner. This will further, impact the availability of DERs during peak load hours and hence support the grid support. Enhancing the existing power handling capacity of the distribution networks will require an immediate huge investment in network capacity extension. This would result in an additional burden on DSOs. Therefore, sharing justified compensation is a good option to avoid immediate large investments and reforms in the existing networks.

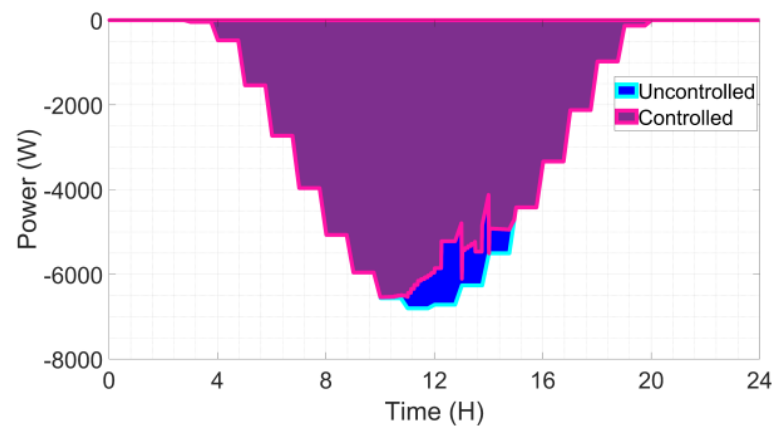

Fig. 7. PV power being injected by house 9

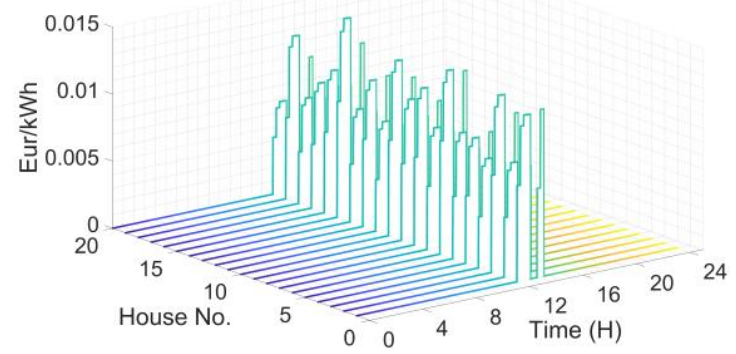

Fig. 8. Compensation for each prosumer

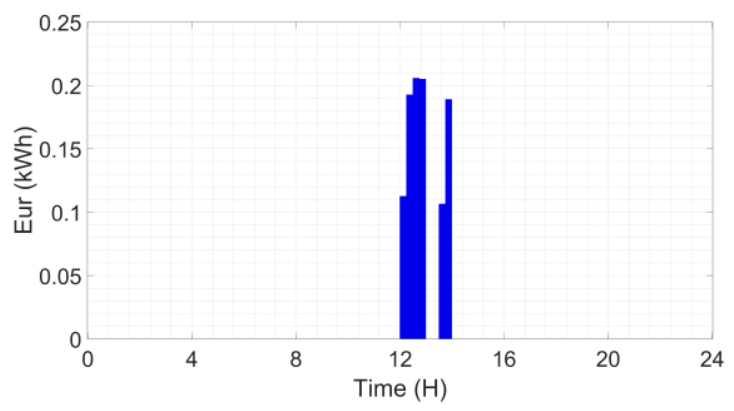

Fig. 9. Total compensation need to be shared by DSO to prosumers

C. Comparison with a day-ahead market price based APC compensation

The network given in Fig. 2, is simulated for a complete one month (June 2016) and compensation cost thus obtained is compared with the compensation estimated based on the day-ahead market prices. Further, a third case is considered by applying a tuning factor (multiplier) with the proposed method, to adjust the proposed compensation with the dayahead market-based compensation. Tuning factor is considered as a country specific parameter and would depend upon the Government policies/energy regulations in that region. The results are given in Fig. 10.

As seen in Fig. 10, compensation calculated based on the proposed methodology is capable to capture the dynamics of electricity day-ahead market price. However, there is a scope for DSO to adjust the compensation cost by tuning the multiplier gain. In this way, depending upon the gain 
objectives, DSOs could decide the closeness of compensation values to the day-ahead market prices. Further, a detailed analysis is required to optimize the tuning parameter, so that techno-social balance could be achieved

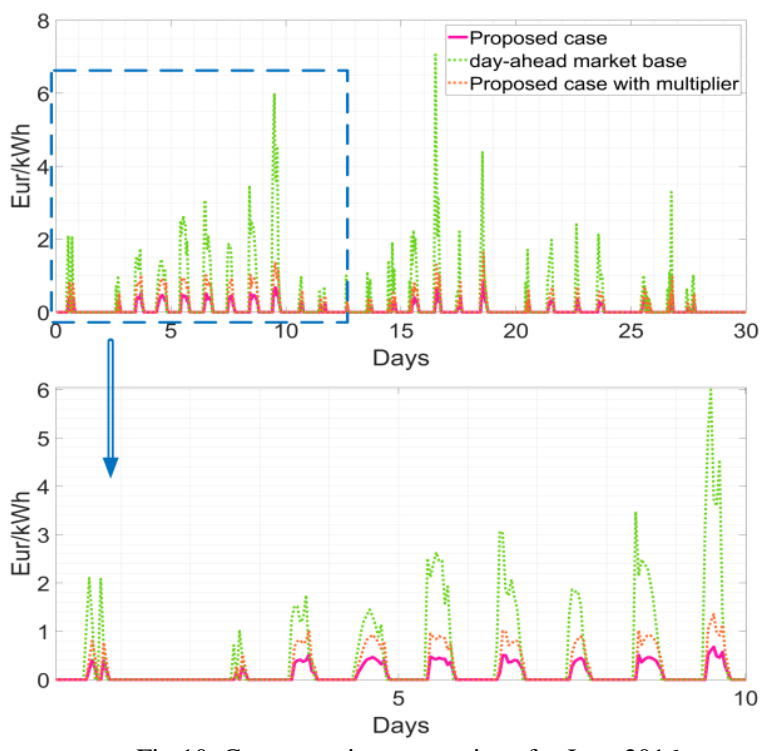

Fig.10. Compensation comparison for June 2016

For the implementation of the proposed compensation method in practice, a more techno-economical exhaustive analysis would be required so, that profits and objectives of the both DSO and prosumers could be preserved. Further, to execute the method, certain changes in the energy polices would also be required. At this point, it seems that proposed methods do not require any capital investments and/or any investments in hardware installations. However, further a more detailed analysis could be carried to analyze the implementation feasibility.

\section{CONCLUSION}

In order to proceed more towards the generation and utilization of green energy, the distribution network should have sufficient capacity to accommodate the high penetration of DERs. Upgradation of existing distribution network capacity needs a huge investment. However, by providing required flexibility and supporting $\mathrm{APC}$, prosumers are serving as assets for DSOs. Therefore, to keep prosumers motivated, the need for developing a simple compensation mechanism for prosumers, who are subjected to APC is realized. In this paper, a compensation mechanism based on the electricity price demand elasticity concept is proposed for APC. The proposed compensation mechanism is simple and effective as simulating results shows that the proposed compensation mechanism can capture the dynamics of the electricity day-ahead market. Results presented in this paper are preliminary and further, a more exhaustive analysis is required to understand the feasibility of the proposed mechanism.

\section{REFERENCES}

[1] Huang, S., Wu, Q., Liu, Z., \& Nielsen, A. H. (2014). Review of Congestion Management Methods for Distribution Networks with
High Penetration of Distributed Energy Resources. In Proceedings of 2014 ISGT Europe (pp. 1-6) IEEE.

[2] Lori Bird, Jaquelin Cochran, and Xi Wang, "Wind and Solar Energy Curtailment: Experience and Practices in the United States", Online available at https://www.nrel.gov/docs/fy14osti/60983.pdf

[3] M. Zeraati, et. al., "A Consensus-Based Cooperative Control of PEV Battery and PV Active Power Curtailment for Voltage Regulation in Distribution Networks," in IEEE Trans. on Smart Grid, vol. 10, no. 1, pp. 670-680, Jan. 2019.

[4] Srete Nikolovski, Hamid Reza Baghaee and Dragan Mlakic, "ANFISBased Peak Power Shaving/Curtailment in Microgrids Including PV Units and BESSs", Energies 2018, 11, 2953.

[5] S. R. Kuppannagari, et.al., "Optimal Net-Load Balancing in Smart Grids with High PV Penetration", in Proc. of $4^{\text {th }}$ ACM Conf. on Systems for Energy-Efficient Built Environments. ACM, USA, 10 pp.

[6] Jingshuang Shen et. al, "Controllable Load Management Approaches in Smart Grids", Energies 2015, 8, 11187-11202.

[7] A. N. M. M. Haque, et.al, "Real-time congestion management in active distribution network based on dynamic thermal overloading cost," 2016 PSCC, Genoa, 2016, pp. 1-7.

[8] M. Brunner, K. Rudion and S. Tenbohlen, "PV curtailment reduction with smart homes and heat pumps", 2016 IEEE International Energy Conference (ENERGYCON), Leuven, 2016, pp. 1-6.

[9] European Renewable Energies Federation, "Dispatching, redispatching and curtailment of renewable energy installations". http://www.erefeurope.org/wp-content/uploads/2019/09/20170407 EREF-BEEPolicy-Brief-Dispatch-Redispatch-und-Curtailment final.pdf

[10] Council of European Energy Regulators, "Status Review of Renewable Support Schemes in Europe for 2016 and 2017". https://www.ceer.eu/documents/104400/-/-/80ff3127-8328-52c34d01-0acbdb2d3bed

[11] "EWEA position paper on priority dispatch of wind power A paper from the EWEA Large-Scale Integration Working Group." (2014).

[12] Klinge Jacobsen, H., \& Schröder, S. T. (2012). Curtailment of renewable generation: Economic optimality and incentives. Energy Policy, 49C, 663-675.

[13] "Wind Europe views on curtailment of wind power and its link to priority dispatch", (2016). https://windeurope.org/wpcontent/uploads/files/policy/position-papers/WindEurope-PriorityDispatch-and-Curtailment.pdf

[14] Yalin Huang and Lennart Soder, "Energy Curtailment Regulation Impact on Distributed Generation Integration", $5^{\text {th }}$ IAEE Asian Conference, 2016

[15] Frank Meissner, Clemens Stiewe, "Curtailment of renewable electricity as a flexibility option", Policy Paper (2019).

[16] E. C. Guardia, A. R. Queiroz and J. W. M. Lima, "Estimation of electricity elasticity for demand rates and load curve in Brazil", IEEE PES General Meeting, Providence, RI, 2010, pp. 1-7.

[17] P. Faria and Z. Vale, "Demand response programs definition using demand price elasticity to define consumers aggregation for an improved remuneration structure", IEEE PES ISGT Europe 2013, Lyngby, 2013, pp. 1-5.

[18] Catia Cialani, Reza Mortazavi, "Household and industrial electricity demand in Europe", Energy Policy 122 (2018) 592-600.

[19] Susana Silva, et.al., "Electricity residential demand elasticities: Urban versus rural areas in Portugal", Energy 144 (2018), 627-632.

[20] Namrata Chindarkar, Nihit Goyal, "One price doesn't fit all: An examination of heterogeneity in price elasticity of residential electricity in India", Energy Economics 81 (2019) 765-778.

[21] Daniel de Abreu Pereira Uhr, et.al., "Estimation of elasticities for electricity demand in Brazilian households and policy implications", Energy Policy 129 (2019) 69-79.

[22] Manuel Frondel, et. al., "Heterogeneity in the price response of residential electricity demand: A dynamic approach for Germany", Resource and Energy Economics 57 (2019) 119-134.

[23] James P. Feehan, "The long-run price elasticity of residential demand for electricity: Results from a natural experiment", Utilities Policy 51 (2018) 12-17.

[24] Marc F. Müller, et. al., "Estimating the price in elasticity of off-grid electricity demand", Development Engineering 3 (2018) 12-22. 